\title{
IDENTIFIKASI GRAVITY WAVES MENGGUNAKAN HIGH PASS FILTER WATER VAPOR BAND SATELIT HIMAWARI DAN DATA MODEL NUMERIK
}

\author{
Gravity waves Identification Using High Pass Filter Water Vapor Band \\ Himawari Satellite and Numerical Model Data
}

\author{
( Kadek Nova Arta Kusuma ${ }^{1)^{\star}}$, Firman Setiabudi ${ }^{1)}$, Eka Fibriantika $^{1)}$, Yunus Subagyo Swarinoto ${ }^{2)}$ \\ 1) Pusat Meteorologi Penerbangan BMKG, Jl. Angkasa 1 No II, Kemayoran, Jakarta Pusat. 10720 \\ 2) Pusat Penelitian dan Pengembangan BMKG, JI. Angkasa 1 No II, Kemayoran, Jakarta Pusat. 10720 \\ *E-mail: ikadeknova_artakusuma@yahoo.co.id
}

\begin{abstract}
Intisari
Di Indonesia, pemanfaatan citra satelit dan model numerik menjadi acuan utama dalam kegiatan operasional cuaca penerbangan. Fenomena cuaca penerbangan yang masih sulit dideteksi adalah clear air turbulence (CAT). Salah satu penyebab terjadinya CAT adalah adanya gravity wave yang terbentuk di atmosfer. Pada paper ini akan ditunjukkan studi kasus fenomena gravity wave yang diidentifikasi menggunakan metode high pass filter pada water vapor band satelit Himawari dan dianalisis menggunakan model ECMWF 0.125 degree. Dari hasil penelitian diperoleh bahwa metode high pass filter dapat membantu mengenali fenomena gravity wave menjadi lebih mudah dalam bentuk paralel strips. Pada studi kasus ini, gravity wave terbentuk karena selisih angin yang besar pada lapisan $200 \mathrm{mb}$ dan $250 \mathrm{mb}$ sehingga membentuk vertical wind shear dan cloud billows yang terdeteksi pada Water Vapor Band dan memiliki pola tegak lurus terhadap angin.
\end{abstract}

Kata Kunci: Gravity Waves, High Pass Filter, Himawari, ECMWF, Clear Air Turbulence

\begin{abstract}
Weather satellite imagery and numerical model prediction become the main reference in aviation weather operations in Indonesia. The aviation weather phenomenon that is still difficult to detect is clear air turbulence (CAT). The presence of gravity waves in the atmosphere is one factor that causes Clear Air Turbulence (CAT). This paper describes the case study of the gravity wave phenomenon, which was identified using a high pass filter method on the Himawari satellite's water vapor band and analyzed using the ECMWF 0.125 degree model. It is found that a high pass filter method can help recognize the gravity wave phenomenon in parallel strips easier. In this case study, the gravity wave is formed by a large wind difference in layers of $200 \mathrm{mb}$ and $250 \mathrm{mb}$ to form vertical wind shear and cloud billows that are detected on the Water Vapor Band and have a vertical pattern to the background wind.
\end{abstract}

Keywords: Gravity Waves, High Pass Filter, Himawari, ECMWF, Clear Air Turbulence

\section{PENDAHULUAN}

Ketika penerbangan sedang dalam fase enroute, pesawat memiliki kemungkinan mengalami clear air turbulence (CAT). Pada dasarnya, CAT hampir tidak mungkin dideteksi dengan instrumen onboard dan mata telanjang, sehingga sulit untuk dihindari oleh pilot. Secara umum, CAT terjadi di langit tak berawan pada ketinggian di atas 6000 meter dan sulit dideteksi oleh radar cuaca yang banyak digunakan saat ini untuk penerbangan sipil (Wu et al., 2018).

Citra satelit terkadang dapat memberikan petunjuk yang berguna tentang keberadaan CAT. Tanda-tanda yang terlihat dalam citra inframerah (IR), visible, dan water vapor (WV) hanya terlihat untuk CAT dalam skala besar (Overeem, 2002).
Indikator yang cukup umum dalam citra satelit kanal inframerah dan visible adalah terlihatnya pita awan cirrus melintang (awan tranversal) yang berorientasi tegak lurus terhadap arah angin. Awan transversal ini sering kali ditemukan pada subtropical jet-stream dekat ekuator (Ellrod, 2000). Awan bergelombang lain yang dapat mengungkapkan keberadaan CAT adalah awan billows yang memiliki jarak teratur dan pola sempit di awan cirrus atau awan tingkat menengah. Seperti pita awan transversal, awan billows juga berorientasi tegak lurus terhadap arah angin. Awan cirrus "billows" mungkin menunjukkan adanya Kelvin Helmholtz Instability (Ellrod, 1989). Awan tranversal ataupun awan billows yang terlihat dalam citra WV dan IR merupakan indikasi adanya turbulensi di 
troposfer atas. Namun, ketiadaan awan-awan bukan merupakan tanda aliran atmosfer tersebut selalu laminar, karena shear-gravity waves hanya terlihat ketika udara hampir jenuh dengan kelembapan tinggi (Eumetrain, 2017).

Munculnya generasi lanjutan dari Advanced Himawari Imager (AHI) dan Advanced Baseline Imager (ABI) diharapkan dapat meningkatkan pengamatan gravity wave, sehingga selanjutnya dapat mengarah ke pengamatan CAT (Wimmers et al., 2018). Pemanfaatan citra satelit Himawari-8 untuk menganalisis proses convective burst dengan gravity waves pada siklon tropis juga telah dilakukan oleh Horinouchi et al. (2020). Feltz et al. (2009) menggunakan citra satelit high resolution water vapor imagery dari MODIS untuk mengidentifikasi keberadaan mountain waves dan turbulensi yang berbahaya.

Penelitian ini dimaksudkan untuk mendeteksi keberadaan gravity waves melalui pemanfaatan citra satelit menggunakan metode High Pass Filter (HPF) pada kasus 28 Maret 2018 di sekitar perairan Kep. Talaud yang kemungkinan merupakan area terjadinya CAT. Studi kasus ini dipilih berdasarkan data Radiosonde di Stasiun Meteorologi Sam Ratulangi Manado yang menunjukkan adanya angin kencang pada atmosfer lapisan atas. Citra WV Satelit Himawari pada tanggal bersangkutan juga mendukung adanya awan tinggi tanpa awan konvektif, sehingga mendukung tujuan penelitian untuk mendeteksi pola awan billows di lapisan atas atmosfer. Menurut Wimmers et al. (2018), penerapan HPF ke kanal water vapor troposfer atas mengungkapkan variasi sub-derajat Kelvin dalam temperatur brightness yang dapat memberi gambaran visual yang berbeda dibandingkan citra aslinya. Rumusan masalah yang dibahas dalam penelitian ini adalah mengetahui kemampuan HPF dalam mendeteksi gravity waves sebagai sumber penghasil CAT, kemudian mengetahui karakteristik angin di sekitar area terbentuknya gravity waves pada studi kasus yang digunakan.

\section{METODE}

Penelitian ini menggunakan data citra satelit Himawari-8 yang memiliki total 16 kanal. Untuk pendeteksian gravity waves menggunakan kanal No. 8 (panjang gelombang $6.2 \mu \mathrm{m}$ ) dan data reanalisis angin ECMWF Numerical Model $0.125^{\circ}$. Menurut Wimmers et al. (2018), panjang gelombang $6.2 \mu \mathrm{m}$ pada $\mathrm{AHI}$ merupakan band yang paling relevan untuk analisis keperluan penerbangan jarak jauh, karena kepekaan terhadap uap air yang tinggi dapat meningkatkan sinyal gelombang gravitasi. Selain itu AHI $6.2 \mu \mathrm{m}$ memang ditujukan untuk pengamatan high level atmospheric water vapor. ECMWF Numerical Model $0.125^{\circ}$ digunakan untuk memperoleh data angin dari lapisan 500 hingga $100 \mathrm{hPa}$ yang akan ditampilkan dalam bentuk cross section dan wind bar. Penelitian ini mengamati keberadaan awan billows pada wilayah $2^{\circ}-6^{\circ} \mathrm{LU}$ dan $126^{\circ}-131^{\circ} \mathrm{BT}$ (di sekitar perairan Kepulauan Talaud) pada tanggal 28 Maret 2018 pukul 12.30 UTC. Data Radiosonde Stasiun Meteorologi Sam Ratulangi - Manado digunakan sebagai data pendukung.

Metode yang digunakan adalah metode High Pass Filter sesuai dengan metode Wimmers et al. (2018). Filter citra yang digunakan dalam penelitian ini adalah Gaussian high-pass convolutional filter. Berikut persamaan yang digunakan,

$$
\begin{gathered}
I_{H P}=\underset{H P}{H}(\sigma) * \mathrm{I} \\
H P(\sigma)=1-\frac{c}{\sigma \sqrt{2 \pi}} \sum e^{-\left(x^{2}+y^{2}\right) / 2 \sigma^{2}}
\end{gathered}
$$

dimana I adalah citra awal, $I_{H P}$ adalah citra yang sudah disaring, asterisk $\left(^{*}\right)$ mengindikasikan konvolusi filter citra dengan citra, $H P(\sigma)$ adalah aditif kebalikan dari filter Gaussian dengan lebar HP parameter $\sigma$, dan $c$ adalah konstanta (Wimmers et al., 2018).

Langkah-langkah penerapan HPF pada citra satelit adalah sebagai berikut:

a. mengekstrak data citra satelit himawari kanal 8 menjadi sebuah matriks yang menunjukkan nilai piksel dengan satuan Kelvin,

b. menerapkan metode fast fourier transform (FFT) pada matriks sehingga membentuk matriks baru $(I)$,

c. membuat matriks filter $H P(\sigma)$ yang berukuran sama dengan matriks sebelumnya berdasarkan rumus $H P(\sigma)$,

d. mengkonvolusi matriks I dengan matriks $H P(\sigma)$ sehingga menghasilkan matriks baru $\left(I_{H P}\right)$,

e. menerapkan invers FFT pada matriks ( $\left.I_{H P}\right)$ dengan satuan (Kelvin) sehingga diperoleh citra satelit baru yang sudah disaring,

f. menerapkan normalisasi data untuk membuat range variasi data dari $-1 \mathrm{~s} / \mathrm{d} 1$.

\section{HASIL DAN PEMBAHASAN}

Untuk mengetahui kemampuan HPF dalam mendeteksi gravity waves, dapat dilihat pada perbandingan citra water vapor (WV) asli dengan yang sudah diterapkan HPF (citra HPF) di Gambar 1. Indikator adanya gravity waves dapat dideteksi melalui citra satelit dengan mengamati adanya pola awan billows. Pola awan billows ini dapat ditemukan pada kotak biru Gambar 1(a). Citra AHI band $6.2 \mu \mathrm{m}$ WV asli (visualisasi abu-abu) mampu menangkap pola billows jika kandungan uap air di atmosfer atas cukup tinggi ditandai oleh warna citra yang semakin putih. Sebagai perbandingannya dengan citra HPF, pola billows juga ditangkap dengan baik pada kotak biru Gambar 1.b. Tetapi, pola billows dengan kandungan uap air sedikit (warna semakin gelap) tidak mampu ditangkap dengan baik oleh citra WV 


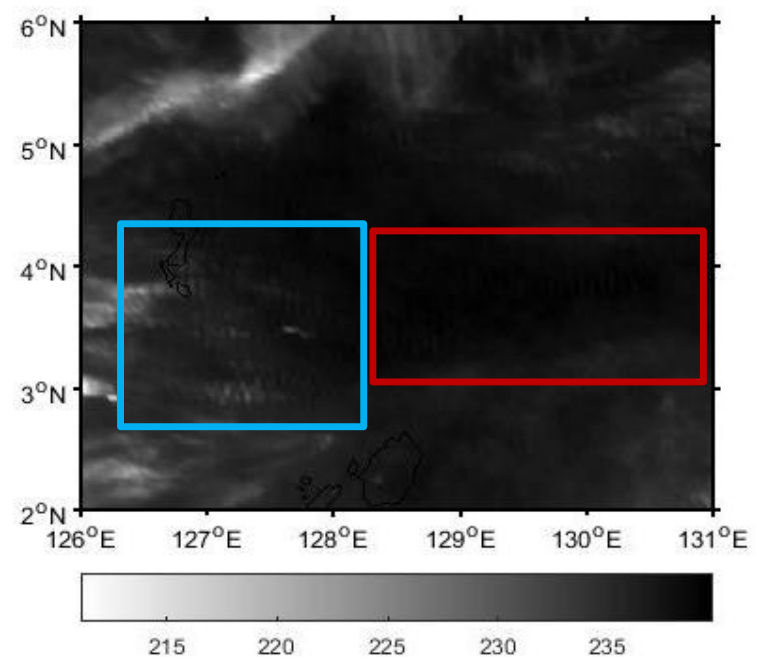

(a)

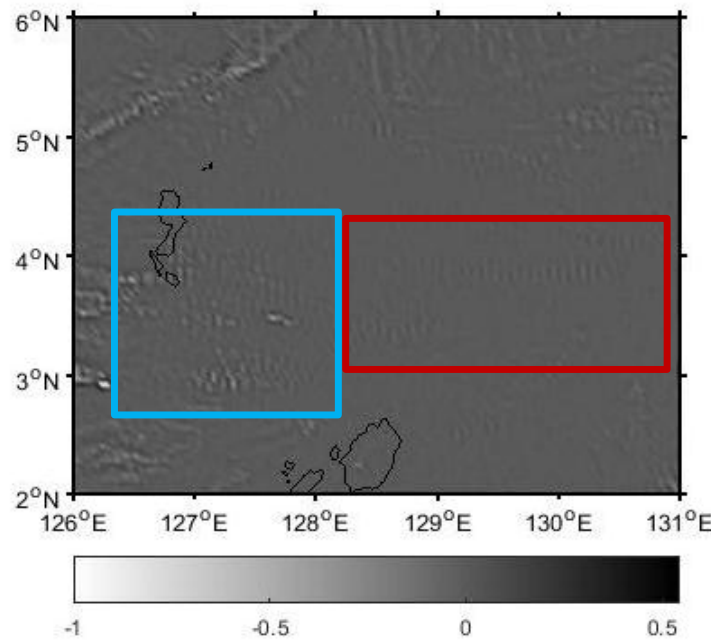

(b)

Gambar 1. Perbedaan antara citra kanal water vapor asli (Kelvin) (a) dengan HPF (tanpa dimensi) (b).

asli (kotak merah Gambar 1.a), sebaliknya citra HPF mampu menangkap pola awan bergelombang ini dengan kondisi hampir sama jelasnya dengan area kandungan uap air tinggi yang dapat dilihat di kotak merah Gambar 1.b.

Penggunaan metode High Pass Filter membuat kontur awan pada citra satelit lebih jelas terlihat dibandingkan dengan citra aslinya. Hal ini mempermudah dalam identifikasi pola billows yang mengindikasikan adanya gravity waves. Perbedaan kedua citra tersebut menunjukan bahwa modifikasi dari variasi nilai sub-derajat menjadi $0.1 \mathrm{~K}$ pada masing-masing pixel menggunakan metode HPF dapat membantu menampilkan uap air yang sangat tipis menjadi kontur-kontur yang dapat dengan mudah dilihat secara visual. Pada citra water vapor asli hanya menggunakan variasi nilai yang lebih besar sehingga lebih sulit untuk menentukan pola yang lebih detil. Variasi nilai -1 sampai dengan 1 pada metode HPF masih relevan digunakan dalam analisis gravity waves. Penggunaan variasi nilai -1

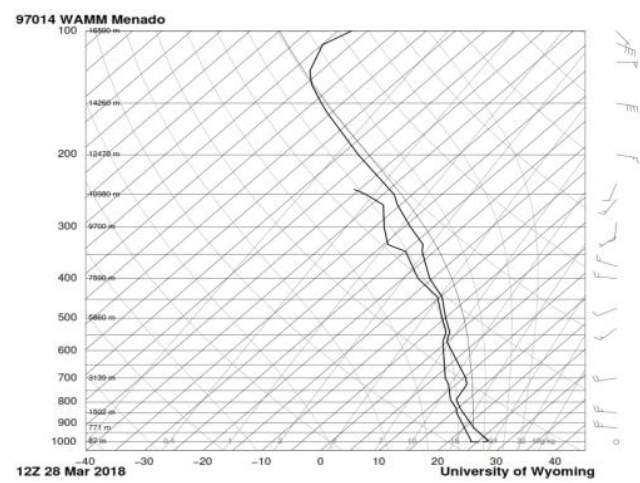

(a) hingga 1 dapat dengan mudah menampilkan fitur gravity waves bahkan untuk citra grayscale dengan kedalaman 8-bit (Wimmers et al., 2018).

Kondisi angin hasil observasi radiosonde (Gambar 2.a) dan model (Gambar 2.b) menunjukan hasil yang relatif sama untuk lapisan $500 \mathrm{hPa}$ hingga $100 \mathrm{hPa}$. Terdapat perubahan arah angin antara lapisan 300 dan $250 \mathrm{hPa}$ dari timuran menjadi baratan. Berdasarkan pengamatan radiosonde, lapisan $150 \mathrm{hPa}(14260 \mathrm{~m})$ terdapat angin dari arah $100^{\circ}$ dengan kecepatan hingga 42 knot, sedangkan pengamatan pada lapisan $200 \mathrm{hPa}(12470 \mathrm{~m})$ dan $250 \mathrm{hPa}(10980 \mathrm{~m})$ menunjukkan arah dan kecepatan angin masing-masing $100 \% 13$ knot dan $215^{\circ} / 10$ knot. Berdasarkan selisih angin antara 3 sampel lapisan yang digunakan, shear yang terbentuk memiliki nilai sekitar 3,7-5 knot per 1000 kaki. Nilai ini memungkinkan untuk membentuk turbulensi lemah hingga sedang berdasarkan WMO (2018).

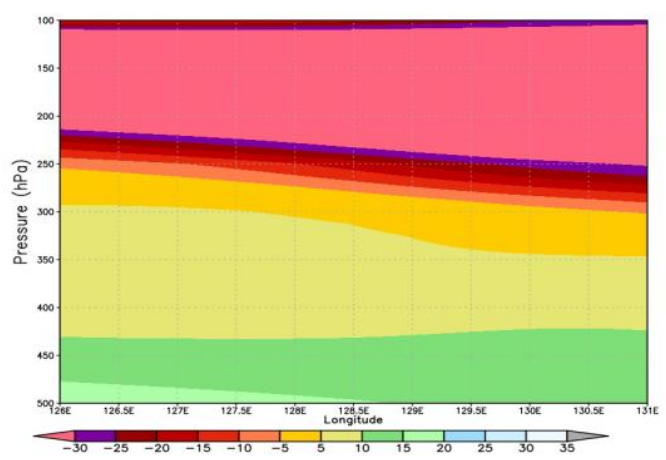

(b)

Gambar 2. Data Radiosonde (a) dan zonal wind (knot) model cross section pada 4 LU (b). 


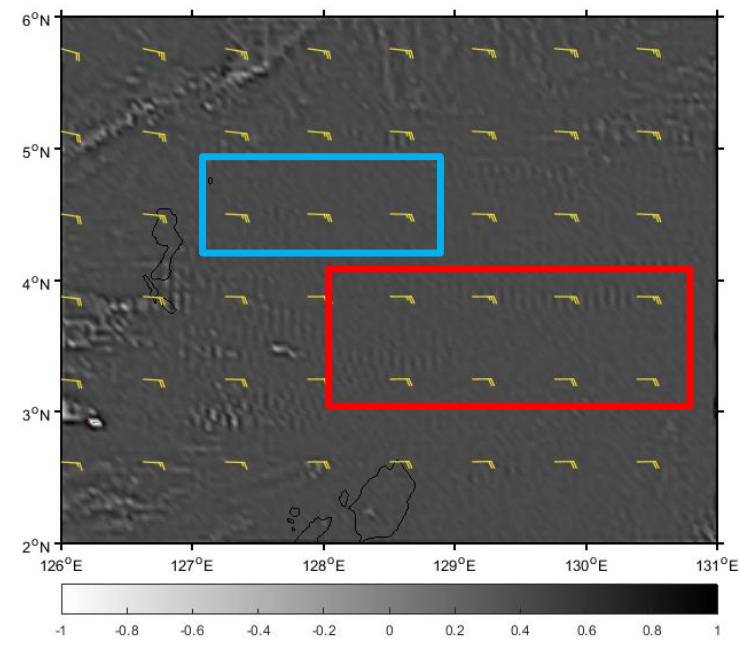

(a)

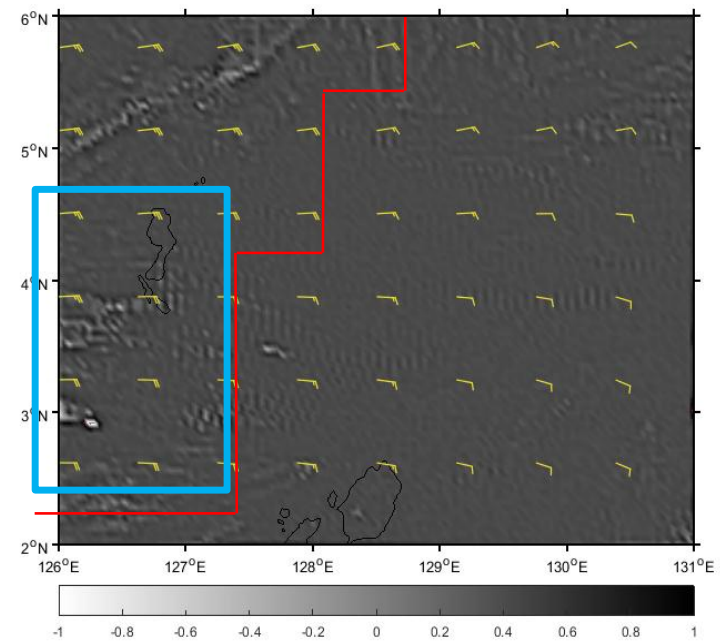

(b)

Gambar 3. Overlay wind bar dengan HPF image (tanpa dimensi), analisis angin $200 \mathrm{mb}$ (a) dan selisih angin lapisan 150-250 $\mathrm{hPa}(\mathrm{b})$.

Gambar 3 menunjukan kondisi angin latar $200 \mathrm{hPa}$ dan nilai shear antara lapisan 150 dan 250 $\mathrm{hPa}$. Strip paralel yang dikenal sebagai pola billows ini menunjukkan adanya gravity waves yang memiliki pola tegak lurus terhadap arah angin latar (Gambar 3.a) maupun arah shear (Gambar 3.b) pada semua area. Ini cukup sesuai dengan Das (2017) yang menyatakan bahwa perbedaan angin horizontal antar lapisan ini memicu ketidakstabilan dinamis akibat adanya shear vertikal sehingga akan membentuk gelombang billows. Pola gelombang billows ini berorientasi tegak lurus terhadap vektor shear dimana amplitudonya dapat tumbuh dan mencapai titik ekstrem kemudian bergulir dan akhirnya pecah menjadi turbulen.

Shimada dan Horinouchi (2018) melakukan kajian terkait vertical wind shear yang kuat pada kasus topan Noul menunjukkan bahwa vertical wind shear memiliki kecepatan angin lebih dari 21 knot. Area sebelah kanan garis merah pada Gambar $3 b$ menunjukkan shear 10-15 knot, sedangkan area di sebelah kiri garis merah menunjukkan shear 20-25 knot. Nilai-nilai ini dapat membuktikan keberadaan Vertical Wind Shear (VWS) di wilayah udara sekitar Kep. Talaud di kedua area dengan intensitas yang berbeda. Jika dibandingkan antara nilai shear dengan billows yang terjadi, billows lebih jelas terlihat pada nilai shear 20-25 knot terutama pada kotak area biru Gambar 3.b. Meskipun demikian, ini belum cukup membuktikan area mana yang menghasilkan turbulen lebih kuat dikarenakan dua alasan. Pertama model ECMWF yang dipakai belum tentu merepresentasikan nilai angin sebenarnya pada kasus tersebut. Kedua, penampakan billows kuat (kotak biru Gambar 3.b) dan penampakan lemah (kotak merah dan biru Gambar 3.a) tidak menunjukkan bahwa area tersebut mengalami turbulensi kuat dan lemah berturut-turut. Kuat lemah penampakan billows di citra satelit lebih ditentukan oleh jenuh atau tidaknya uap air yang berada di area itu (Eumetrian, 2017).

\section{KESIMPULAN}

Metode High Pass Filter (HPF) dapat membantu mengidentifikasi wilayah pola garis paralel pada citra water vapor lebih jelas dibandingkan menggunakan citra WV aslinya bahkan dengan kondisi uap air yang cukup rendah. Pola garis paralel "billows" mengindikasikan adanya gravity waves yang dapat menyebabkan turbulensi atmosfer. Pada kasus ini gravity waves terbentuk oleh perbedaan angin yang cukup besar antara lapisan 250 dan $150 \mathrm{mb}$ yang membentuk vertical wind shear (VWS). VWS ini menciptakan pola garis parallel dalam bentuk awan yang terdeteksi dalam Water Vapor Band dan memiliki pola angin tegak lurus terhadap angin latar.

Diperlukan studi lebih lanjut dengan menggunakan data satelit beresolusi lebih tinggi untuk membuktikan besarnya turbulensi dalam pola gravity waves, intensitas turbulensi dari pengamatan pesawat sangat diperlukan.

\section{DAFTAR PUSTAKA}

Das, Subrata, Das, S., Saha, K., Krishna, M., Dani, K. (2017). Investigation of KelvinHelmholtz Instability in The Boundary Layer using Doppler Lidar and Radiosonde Data. Atmospheric Research 202. doi:10.1016/j.atmosres.2017.11.013.

Ellrod, G.P. (1989). A Decision Tree Approach to Clear Air Turbulence Analysis Using Satellite and Upper Air Data. NOAA Technical Memorandum NESDIS 23, Satellite Applications Laboratory, Washington.

Ellrod, G.P., (2000). Satellite Images Provide Valuable Information Supplement to The 
Aviation Meteorologist. ICAO Journal 55(2), 6-10.

Eumetrian.

(2017). Gravity Waves http://www.eumetrain.org/data/4/452/navme nu.php?tab=7\&page $=1.0 .0$. (diakses tanggal 13 Agustus 2020)

Feltz, W.F., Bedka, K.M., Otkin, J.A., Greenwald, T., Ackerman, S.A. (2009). Understanding Satellite-Observed Mountain-Wave Signatures Using High-Resolution Numerical Model Data. Weather and Forecasting 24(1), 76-86. doi: 10.1175/2008WAF2222127.1.

Horinouchi, T., Shimada, U., Wada, A. (2020). Convective Bursts With Gravity Waves in Tropical Cyclones: Case Study With the Himawari - 8 Satellite and Idealized Numerical Study. Geophysical Research Letters, 47(3). doi: 10.1029/2019GL086295

Overeem A., (2002). Verification of clear-air turbulence forecasts, Technisch rapport, KNMI

Shimada, U., Hironouchi, T. (2018). Reintensification and Eyewall Formation in
Strong Shear: A Case Study of Typhoon Noul (2015). Monthly Weather Review, 146(9), 2799-2817. doi: 10.1175/MWR-D18-0035.1.

Wimmers, Anthony, Griffin, S., Gerth, J., Bachmeier, S., Lindstrom, S. (2018). Observations of Gravity waves with HighPass Filtering in the New Generation of Geostationary Imagers and Their Relation to Aircraft Turbulence. Weather and Forecasting 33(1). doi: 10.1175/WAF-D-170080.1.

WMO. (2018). Aviation Hazards. AeM Series No. 3, Commission for Aeronautical Meteorology. Switzerland: Chair, Publications Board World Meteorological Organization (WMO)

Wu, Renbiao, Fan, Y., Lu, X., Zhang, Z., Li, H. (2018). Detection of Clear Air Turbulence by Airborne Weather Radar using RR-MWF Method. 2018 IEEE/AIAA 37th Digital Avionics Systems Conference (DASC). doi: 10.1109/DASC.2018.8569571. 